\title{
OPTIMISME PADA WANITA PENDERITA KANKER PAYUDARA BERUSIA DEWASA TENGAH
}

\author{
Sherly ${ }^{1}$, Mutiara Mirah Yunita ${ }^{2}$
}

${ }^{1}$ Program Studi Psikologi, Universitas Bunda Mulia

Email: sherlyjiaen97@gmail.com

\begin{abstract}
ABSTRAK
Penyakit kanker payudara merupakan salah satu penyebab kematian utama di dunia, termasuk di Indonesia. Prevalensi kasus dari penyakit kanker payudara juga meningkat dari tahun ke tahun. Kanker payudara merupakan penyakit yang dapat mempengaruhi setiap aspek kehidupan manusia dan dapat menimbulkan masalah-masalah baik secara psikis maupun psikologis. Secara fisik, penderita akan merasakan banyak gangguan fisik seperti mual, muntah, kerontokan yang parah, dan gangguan fisik lainnya. Secara psikologis, penderita akan merasa kaget, sedih, cemas, bahkan hingga depresi. Tidak sedikit individu yang beranggapan bahwa diagnosis kanker merupakan sebuah kalimat yang mematikan, meskipun pada kenyataannya tidak selalu seperti itu. Oleh karena itu, optimisme merupakan suatu aspek yang sangat penting bagi penderita kanker payudara. Ketika individu memiliki optimisme untuk sembuh, maka individu akan memiliki kesehatan psikologis, sehingga tetap berusaha untuk melakukan hal-hal untuk mencapai kesembuhan, tidak putus asa, serta memiliki kepastian untuk memandang masa depan. Penelitian ini menggunakan metode penelitian kualitatif jenis deskriptif dengan teknik wawancara dan observasi untuk mengumpulkan data. Penelitian ini dilakukan kepada wanita berusia dewasa tengah dengan rentang usia 40 - 65 tahun. Hasil penelitian ini dapat disimpulkan bahwa kelima subyek memiliki optimisme dalam berjuang melawan penyakit kanker payudara. Meski kualitas optimisme pada masing-masing subyek tidak sepenuhnya sama, namun, secara keseluruhan mereka dapat dikatakan optimis dalam menjalankan pengobatannya. Adapun terdapat faktorfaktor yang secara signifikan mempengaruhi optimisme pada subyek yaitu faktor kemampuan koping untuk mengatasi persoalan yang terjadi sepanjang pengobatan mereka, faktor dukungan sosial, faktor status kesehatan, faktor spiritualitas, dan motivasi dalam diri.
\end{abstract}

Kata Kunci: Kanker Payudara, Wanita berusia Dewasa Tengah, Optimisme

\begin{abstract}
Breast cancer is one of the main causes of death in the world, including in Indonesia. The prevalence of cases of breast cancer also increases from year to year. Breast cancer is a disease that can affect every aspect of human life and can cause problems both psychologically and psychologically. Physically, the patient will feel many physical disorders such as nausea, vomiting, severe loss, and other physical disorders. Psychologically, the patient will feel shocked, sad, anxious, even to depression. Not a few individuals who think that the diagnosis of cancer is a deadly sentence, though in reality it is not always that way. Therefore, optimism is a very important aspect for breast cancer patients. When they have optimism to heal, then they will have psychological health, so keep trying to do things to achieve healing, not despair, and have the certainty to look at the future. This research uses descriptive qualitative research method with interview and observation technique to collect data. This study was conducted for middle aged women with age range 40-65 years. The results of this study can be concluded that the five subjects had optimism in fighting breast cancer. Although the quality of optimism in each subject is not entirely the same, however, overall they can be said to be optimistic in carrying out their treatment. There are several factors that influence their optimism include factors of coping ability to overcome problems that occur throughout their treatment, social support factors, health status factors, spirituality factors, and internal motivation.
\end{abstract}

Keywords: Breast Cancer, Middle Adult Women, Optimism

\section{PENDAHULUAN}

\section{Latar Belakang}

Penyakit kanker menjadi salah satu penyebab kematian utama di dunia. Berdasarkan data Global Burden Cancer (GLOBOCAN) International Agency for Research on Cancer (IARC), pada 2012 terdapat 14.067.894 kasus baru dan 8.201.575 kematian akibat kanker. Kanker payudara, kanker prostat, dan kanker paru merupakan jenis kanker dengan persentase kasus 
baru tertinggi, besarannya hingga 43,3\%, 30,7\%, dan 23,1\% (Adnan, 2016). Berdasarkan informasi Kementrian Kesehatan RI, secara nasional prevalensi penyakit kanker pada penduduk semua umur di Indonesia tahun 2013 sebesar 1,4\% atau diperkirakan sekitar 347.792 orang. Kementerian Kesehatan mencatat dari sekian banyak kanker yang menyerang penduduk Indonesia, penyakit kanker serviks dan payudara merupakan penyakit kanker dengan prevalensi tertinggi di Indonesia pada tahun 2013, yaitu kanker serviks sebesar 0,8\% dan kanker payudara sebesar 0,5\%. (Manafe, 2014). Data Kementerian Kesehatan 2016 menunjukkan, wanita paling banyak terdiagnosa kanker payudara. Jumlah yang diperiksa dari Februari - Desember 2015 adalah sebanyak 3.427 jiwa (Kania, 2016).

Berdasarkan data tertulis Yayasan Kanker Indonesia Provinsi DKI Jakarta (2015), kanker payudara merupakan jenis kanker nomor dua terbanyak pada wanita di Indonesia. Kanker payudara ialah kanker yang berasal dari kelenjar, saluran kelenjar, dan jaringan penunjang payudara, tidak termasuk kulit payudara. Direktur Utama sekaligus spesialis bedah onkologi Rumah Sakit Dharmais mengungkapkan bahwa jumlah kasus kanker payudara di RS Dharmais meningkat setiap tahun (Riady, 2013). Berdasarkan data Kementerian Kesehatan RI, pervalensi jumlah kasus baru dan jumlah kematian pada pasien penderita kanker payudara di Rumah Sakit Kanker Dharmais tahun 2013 merupakan jumlah kasus dan kematian tertinggi dibandingkan kanker lainnya; antara lain, jumlah kasus baru mencapai angka 819 dan jumlah kematian mencapai angka 217. Risiko kanker payudara lebih besar terjadi pada usia wanita diatas 40 tahun (Gale \& Charette, 1999) atau di masa dewasa tengah (Sari, 2012).

Kanker payudara merupakan penyakit yang dapat mempengaruhi setiap aspek kehidupan manusia dan dapat menimbulkan masalah-masalah fisiologis, psikologis, dan sosial (Suharmilah, Setyaningsih, \& Wijayana, 2013). Pengobatan penyakit kanker ini juga dapat menimbulkan gangguan fisik lain, seperti kerontokan rambut, muntah, mual, dan kelelahan (Winda dan Sudiantara, 2014). Reaksi psikologis yang dapat muncul setelah pasien didiagnosis kanker payudara pada umumnya merasa shock mental, takut, tidak bisa menerima kenyataan, sampai pada keadaan depresi (Suharmilah, Setyaningsih, \& Wijayana, 2013). Tidak sedikit individu yang beranggapan bahwa diagnosis kanker merupakan sebuah kalimat yang mematikan, meskipun pada kenyataannya tidak selalu seperti itu (Feldman, 2011). Saheen, dkk. (2011), dalam hasil penelitiannya mengungkapkan bahwa ada beberapa reaksi pasien atas kanker payudara, antara lain, pertama, reaksi pasien itu sendiri atas diagnosis penyakit, $80 \%$ pasien mengatakan bahwa mereka menjadi sangat depresi, $16 \%$ pasien mengatakan bahwa mereka merasa kematian semakin dekat, dan sisanya ketika mendengar berita tentang penyakitnya menjadi terganggu namun memiliki kemauan keras akan melawan penyakitnya, kedua reaksi dari suami pasien atas diagnosis pada istrinya juga sangat mengganggu kestabilan diri penderita kanker payudara tersebut.

Reaksi suami tergantung dari tingkat pendidikan dan kesadaran akan kanker payudara tersebut. 44\% pasien mengatakan bahwa ketika ia mendengar berita mengenai diagnosis ini, suami mereka menjadi terganggu dan menunjukkan sikap kurang kooperatif, 32\% menunjukkan sikap kooperatif, $32 \%$ suami meminta bercerai, dan sisanya menunjukkan dukungan penuh dan mendorong untuk melawan penyakitnya, ketiga, diagnosis atas penyakit kanker payudara juga menimbulkan efek pada kehidupan sosialnya. Setelah diagnosis atas penyakit tersebut, beberapa penderita menarik diri dari aktivitas sosial. $72 \%$ mengatakan bahwa kehidupan sosial para penderita ini menjadi terganggu, 19\% mengatakan memutuskan menjauh dari lingkungan sosialnya, dan sisanya mengatakan bahwa kanker payudara tidak memberikan efek pada kehidupan sosialnya (dalam Winda dan Sudiantara, 2014). Mitgaard, Stelter, Rorth, \& Adamsen 
(2007) mengatakan bahwa pengaruh tidak menyenangkan juga dirasakan pasien saat harus menjalani pengobatan yang lama, ketidaknyamanan karena reaksi obat, dan tingginya biaya (dalam Saniatuzzulfa \& Retnowati, 2015). Meskipun ketakutan tersebut sama pada setiap pasien tetapi memiliki tingkat tekanan psikologis yang berbeda, hal tersebut berkaitan dengan kondisi medis, aspek psikologis, dan aspek sosial (Saniatuzzulfa \& Retnowati, 2015).

Faktor kepribadian individu turut berperan dalam kondisi psikologis individu penderita kanker. Seperti contoh, pasien kanker yang lebih optimis melaporkan lebih sedikit mengalami distres fisik maupun psikis dibandingkan pasien kanker yang optimismenya lebih rendah (Fieldman, 2011). Wardiyah, Afiyanti, \& Budiati (2014) juga mengatakan bahwa salah satu faktor yang mempengaruhi adaptasi seseorang yang baru saja terdiagnosa kanker adalah optimisme terhadap kesembuhan. Optimisme merupakan kemampuan seseorang untuk menginterpretasi secara positif segala kejadian dan pengalaman dalam kehidupannya (Primardi \& Hadjam, 2010). Baumgardner \& Crothers (2010) menyatakan bahwa optimisme membuat individu untuk tetap percaya bahwa individu dapat mencapai tujuan yang diinginkan, sedangkan pesimisme ragu akan kemampuannya. Pesimis memiliki lebih banyak pandangan negatif dan memfokuskan pada apa yang hilang (dalam Cahyasari \& Sakti, 2014). Peneliti menyimpulkan bahwa pasien-pasien dengan tingkat optimisme kesembuhan yang tinggi akan memiliki kondisi kesehatan dan daya tahan tubuh yang lebih baik dibandingkan pasien-pasien yang cenderung pesimis atau memiliki tingkat optimisme kesembuhan yang rendah.

Rahmah \& Widuri (2011) berpendapat bahwa penderita kanker yang optimis lebih mampu untuk memusatkan perhatian dan sumber daya pada hal-hal yang paling penting, dan melepaskan diri dari duka dan masalah yang tak terkendali serta secara bertahap menerima kesulitan sehingga memungkinkan proses penyembuhan (dalam Dewi, Mayangsari, \& Fauzia, 2016). Optimisme menjadikan individu memiliki energi tinggi, serta bekerja keras untuk melakukan hal yang penting demi mencapai kesembuhan yang diinginkan. Ketika individu memiliki optimisme untuk sembuh, maka individu akan memiliki kesehatan psikologis, sehingga tetap berusaha untuk melakukan hal-hal untuk mencapai kesembuhan, tidak putus asa, serta memiliki kepastian untuk memandang masa depan (Cahyasari \& Sakti, 2014).

Seligman (2006) mengemukakan bahwa optimisme dan pesimisme mempengaruhi kesehatan. Optimisme dapat membantu meningkatkan kesehatan secara psikologis, sehingga diharapkan akan mempengaruhi perilaku individu ke arah yang positif (dalam Cahyasari \& Sakti, 2014). Peterson (2006) mengatakan bahwa semakin tinggi tingkat optimisme individu maka akan semakin tinggi pula potensi pengaruhnya terhadap kesejahteraan individu tersebut. Berdasarkan hal tersebut, penulis menyimpulkan bahwa tingkat optimisme pada pasien secara tidak langsung akan mempengaruhi kesehatan dan daya tahan tubuh pasien.

\section{Rumusan Masalah}

Berdasarkan fenomena yang dikaji mengenai pentingnya optimisme bagi wanita penderita kanker payudara, maka peneliti ingin melihat bagaimana optimisme pada wanita penderita kanker payudara berusia dewasa tengah dan faktor-faktor yang mempengaruhi optimisme pada wanita penderita kanker payudara berusia dewasa tengah.

\section{METODE PENELITIAN Partisipan Penelitian}

Jenis penelitian yang dilakukan berupa jenis penelitian kualitatif dengan tipe penelitian studi kasus deskriptif. Kriteria atau karakteristik partisipan dalam penelitian ini adalah wanita berusia 
40 - 65 tahun di Indonesia yang menderita kanker payudara. Partisipan dalam penelitian ini berjumlah 5 (lima) orang subyek yang sesuai dengan kriteria atau karakteristik partisipan yang telah ditentukan oleh peneliti.

\section{Metode Pengumpulan Data}

Pada penelitian kali ini, peneliti akan melakukan observasi dan wawancara terhadap kelima partisipan penelitian. Peneliti juga akan menggunakan alat bantu sekunder untuk menunjang pengumpulan data yakni berupa pedoman wawancara, rekaman arsip, dan dokumentasi.

\section{Teknik Analisa Data}

Sebelum proses menganalisa data, langkah awal yang terlebih dahulu akan peneliti lakukan ialah melakukan proses koding. Koding dimaksudkan untuk dapat mengorganisasi dan mengsistemasi data secara lengkap dan mendetail sehingga data dapat memunculkan gambaran tentang topik yang diteliti. Berikutnya, peneliti akan menggunakan teknik analisis tematik dengan pendekatan induktif, dimana seluruh data-data yang diperoleh akan diurai dan dianalisa satu per satu hingga membentuk suatu kesimpulan.

\section{HASIL DAN PEMBAHASAN}

Tabel 1. Karakteristik Partisipan

\begin{tabular}{llllll}
\hline & Subyek 1:U & Subyek 2:P & Subyek 3:Z & Subyek 4:P & Subyek 5:N \\
\hline Usia & 44 tahun & 64 tahun & 53 tahun & 58 tahun & 51 tahun \\
\hline $\begin{array}{l}\text { Jenis } \\
\text { Kelamin }\end{array}$ & Perempuan & Perempuan & Perempuan & Perempuan & Perempuan \\
\hline Pekerjaan & $\begin{array}{l}\text { Financial } \\
\text { Accounting }\end{array}$ & $\begin{array}{l}\text { Pelatih } \\
\text { Pramuka }\end{array}$ & $\begin{array}{l}\text { Usaha } \\
\text { Konveksi }\end{array}$ & $\begin{array}{l}\text { Pensiunan } \\
\text { Wiraswasta }\end{array}$ & $\begin{array}{l}\text { PNS bagian } \\
\text { Pengemban } \\
\text { gan Pasar }\end{array}$ \\
\hline Agama & Islam & Islam & Islam & Buddha & Islam \\
\hline Status & Menikah & Janda & Menikah & Menikah & Menikah \\
\hline $\begin{array}{l}\text { Tingkat } \\
\text { Kanker } \\
\text { Stadium }\end{array}$ & $\begin{array}{l}\text { 2A di } \\
\text { payudara } \\
\text { sebelah kiri }\end{array}$ & 2B & 2B & 3B & Grade 2 \\
\hline $\begin{array}{l}\text { Waktu } \\
\text { terdiagnosa }\end{array}$ & 2014 & 2016 & 2016 & 2016 & 2016 \\
\hline
\end{tabular}

Berdasarkan hasil wawancara terhadap kelima subyek (U, P, Z, G, N), dapat terlihat bahwa kelima subyek (U, P, Z, G, N) memiliki optimisme dalam menghadapi penyakit dan menjalani proses pengobatan mereka. Pada dimensi permanence, subyek U, P, G, dan N menunjukkan optimisme saat mengadapi dan menyikapi berbagai peristiwa terkait penyakit dan juga proses pengobatan mereka. Kelima subyek cenderung dapat memandang peristiwa yang buruk yang terjadi dalam kehidupan mereka sebagai sesuatu yang bersifat sementara, serta memandang bahwa terjadinya suatu peristiwa baik disebabkan oleh hal-hal yang bersifat lebih permanen. Saat ini, kelima subyek, sama-sama memiliki keyakinan akan sembuh dari penyakit kanker payudara. Namun, berbeda dengan subyek Z, yang mana juga menunjukkan optimismenya pada dimensi permanence, namun, terdapat sebuah anggapan subyek terkait penyakitnya dimana subyek $\mathrm{Z}$ tidak menunjukkan optimismenya dari sisi permanence. Subyek $\mathrm{Z}$ beranggapan bahwa dalam kehidupan ini, tidak ada satu hal pun yang pasti selain daripada kematian, sehingga, ia tidak beranggapan bahwa dirinya pasti sembuh dari penyakit yang dideritanya saat ini. Bagi subyek Z, satu-satunya hal yang pasti di dalam dunia ini ialah kematian itu sendiri. Namun, anggapannya 
tersebut tidak membuatnya berputus asa atau enggan berobat. Subyek $\mathrm{Z}$ tetap semangat dalam menjalankan pengobatannya dan berusaha untuk sembuh. Sedangkan, untuk beberapa peristiwa lainnya dilihat dari dimensi permanence subyek $\mathrm{Z}$ tetap menunjukkan optimisme dari dimensi permanence.

Pada dimensi pervasiveness, subyek U, P, G, dan Z menunjukkan optimisme saat mengadapi dan menyikapi berbagai peristiwa terkait penyakit dan juga proses pengobatan mereka. Kelima subyek cenderung dapat memandang peristiwa yang buruk yang terjadi dalam kehidupan mereka sebagai satu bagian yang spesifik dan tidak berpengaruh ke seluruh area kehidupan mereka, serta memandang suatu peristiwa baik yang terjadi dalam kehidupan mereka dari sisi universal atau keseluruhan. Berbeda dengan subyek $\mathrm{N}$, yang mana juga menunjukkan optimismenya pada dimensi pervasiveness, namun, terdapat sebuah anggapan subyek terkait penyakitnya dimana subyek $\mathrm{N}$ tidak menunjukkan optimismenya dari sisi pervasiveness. Subyek N mengatakan bahwa beberapa kali saat ia mengalami down pada tubuhnya, akan terlintas di benaknya pikiranpikiran seperti kemungkinan mengalami metastase, atau bahkan kemungkinan akan kematian. $\mathrm{N}$ juga sempat menggeneralisasikan bahwa semua individu yang memiliki posisi yang sama dengan $\mathrm{N}$, dalam arti juga tengah berjuang melawan penyakit, pasti akan memiliki pemikiran yang demikian di saat-saat tertentu. Meski demikian, tingkat optimisme subyek $\mathrm{N}$ pada dimensi ini masih dapat dikategorikan cukup, dikarenakan pada saat di benak subyek $\mathrm{N}$ mulai bermunculan hal-hal yang negatif, ia akan segera menepis pemikiran-pemikiran tersebut dan menggantinya dengan pemikiran yang positif. Serta, di beberapa peristiwa lain, subyek $\mathrm{N}$ tetap menunjukkan optimisme dari dimensi pervasiveness.

Pada dimensi personalization, kelima subyek (U, P, Z, G, N) menunjukkan optimisme saat mengadapi dan menyikapi berbagai peristiwa terkait penyakit dan juga proses pengobatan mereka. Kelima subyek cenderung dapat memandang peristiwa yang buruk yang terjadi dari faktor eksternal sebagai penyebab, dan memandang terjadinya peristiwa baik disebabkan oleh faktor internal. Pada dimensi ini, kelima subyek memiliki tingkat optimisme yang baik. Meski ada saat dimana mereka merenungkan ke arah internal diri mereka sendiri alasan mereka dapat terkena penyakit kanker payudara, namun, pada akhirnya mereka cenderung mampu menemukan hikmah dan sisi positif yang dapat dipetik melalui penyakit yang dilalui.

Berdasarkan hasil wawancara, dapat disimpulkan bahwa saat ini kelima subyek memiliki keyakinan untuk sembuh dari penyakit kanker payudara dan kelima subyek sungguh-sungguh menjalankan pengobatan serta menjaga kesehatannya dengan maksimal. Terhadap berbagai efek samping kemoterapi yang dialami, kelima subyek mampu melaluinya dengan baik dan paham bahwa hal tersebut hanya bagian dari efek samping kemoterapi dan akan berlalu setelah proses kemoterapi selesai. Terhadap hambatan fisik yang dialami seperti tangan yang menjadi golden hand, kelima subyek juga mampu menerima dan menghadapinya serta memahami bahwa hal tersebut merupakan resiko dan bagian daripada proses pengobatan mereka. Meskipun ada kalanya mengalami masa down pada saat terjadi suatu permasalahan, namun mereka mampu mengubah pola pikir mereka dan kembali fokus untuk mencari solusi, serta tidak menyerah pada perjuangan mereka. Beberapa faktor yang mempengaruhi optimisme mereka, antara lain faktor kemampuan koping untuk mengatasi persoalan yang terjadi sepanjang pengobatan mereka, faktor dukungan sosial, faktor status kesehatan, faktor spiritualitas, dan motivasi dalam diri.

\section{KESIMPULAN DAN SARAN Kesimpulan}


Berdasarkan hasil analisa yang dilakukan, diketahui bahwa kelima subyek memiliki optimisme dalam berjuang melawan penyakit kanker payudara. Meski kualitas optimisme pada masingmasing subyek tidak sepenuhnya sama, namun, secara keseluruhan mereka dapat dikatakan optimis dalam menjalankan pengobatannya. Dengan permasalahan dan perjalanan pengobatan yang berbeda-beda antara satu sama lain, sekalipun disaat mereka pernah mengalami down, pada akhirnya mereka mampu untuk kembali bangkit dan berusaha mengatasi setiap kejadian dengan baik dan tetap berjuang untuk sembuh.

Peneliti menyimpulkan beberapa faktor yang mempengaruhi optimisme mereka, antara lain faktor kemampuan koping untuk mengatasi persoalan yang terjadi sepanjang pengobatan mereka, faktor dukungan sosial, faktor status kesehatan, faktor spiritualitas, dan motivasi dalam diri. Sedangkan, dampak dari optimisme itu sendiri, dengan adanya keyakinan dan harapan untuk sembuh, menjadikan mereka lebih sehat secara fisik dan menjadi lebih semangat untuk menjalani pengobatannya hingga mencapai kesembuhan tersebut, serta lebih semangat dalam menjalani kegiatan dan sktivitas sehari-hari mereka. Dengan adanya optimisme, kelima subyek dapat menjalankan kesehariannya tanpa dipenuhi perasaan sedih, murung, dan juga tidak terpuruk di dalam penyakit yang dideritanya. Bahkan, terdapat subyek yang melalui penyakit yang dialami serta proses dan pengalaman yang dilalui, mereka pun termotivasi untuk berbagi pengalaman mereka pada orang lain dan menjadi penyemangat serta inspirasi bagi orang lain.

\section{Saran}

Bagi pengembangan penelitian selanjutnya, disarankan agar pihak peneliti dapat melakukan observasi yang lebih panjang dan lebih mendalam terhadap setiap subyek. Observasi dapat dilakukan di saat-saat tertentu, dengan tujuan agar peneliti dapat melihat secara langsung bagaimana subyek menghadapi dan menyikapi berbagai peristiwa yang dialami terkait penyakit dan proses pengobatannya. Berikutnya, disarankan agar pihak peneliti dapat memilih partisipan dengan usia yang homogen agar dapat dibuat perbandingan.

\section{Ucapan Terima Kasih (Acknowledgement)}

Dalam penyusunan karya ilmiah ini, peneliti sepenuhnya menyadari bahwa selesainya laporan karya ilmiah ini tidak terlepas dari dukungan, semangat, serta bimbingan dari berbagai pihak, baik bersifat moril maupun materil. Oleh karena itu, penulis ingin menyampaikan ucapan terima kasih yang sebesar-besarnya kepada :

1. Ibu Shanty Sudarji M, Psi., Psikolog, selaku Ketua Program Studi Psikologi Fakultas Ilmu Sosial dan Humaniora Universitas Bunda Mulia yang telah membagikan ilmu dan pengalamannya pada peneliti, juga telah banyak memberikan bimbingan yang sangat berarti bagi peneliti selama peneliti menjalani masa perkuliahan.

2. Ibu Mutiara Mirah Yunita, S.Psi., M.Psi, selaku Dosen Pembimbing Skripsi yang telah bersedia memberikan waktu, pikiran, tenaga, ilmu, masukan, saran, dan semangat yang sangat berarti bagi peneliti dalam menyelesaikan karya ilmiah ini.

3. Seluruh dosen Program Studi Psikologi Universitas Bunda Mulia yang telah bersedia membagikan ilmu dan pengalamannya kepada peneliti selama menjalani masa perkuliahan.

4. Seluruh pihak yang tidak dapat peneliti sebutkan satu per satu, yang telah membantu dan mendukung peneliti dalam menyelesaikan karya ilmiah ini sehingga dapat terselesaikan dengan baik.

Peneliti berharap karya ilmiah ini dapat memberikan kontribusi bagi kemajuan ilmu pendidikan, khususnya bidang keilmuan Psikologi, dan bermanfaat bagi siapapun yang membacanya. Penyusunan karya ilmiah ini disusun dengan sebaik-baiknya, namun penulis sepenuhnya 
menyadari bahwa karya ilmiah ini masih jauh dari kata sempurna. Untuk itulah peneliti sangat mengharapkan saran dan kritik yang bersifat membangun untuk penyempurnaan karya ilmiah ini. Atas perhatiannya, penulis mengucapkan terima kasih.

\section{REFERENSI}

Adnan, S. A. (2016, Mei 12). Mengupas masalah penanganan kanker di Indonesia. Retrieved from http://news.metrotvnews.com/read/2016/05/12/527356/mengupas-masalahpenanganan-kanker-di-indonesia

Cahyasari, A. M. S. M., Sakti, H. (2014). Optimisme kesembuhan pada penderita mioma uteri. Jurnal Psikologi Undip, 13(1), 21-33.

Dewi, E. Y. S. S., Mayangsari, M. D., Fauzia, R. (2016). Hubungan antara adversity quotient dengan resiliensi pada penderita kanker stadium lanjut.

Fieldman, R. S. (2011). Development across the life span sixth edition. United States of America : Pearson Education, Inc.

Kania, D. (2016, September 7). Banyaknya pemicu kanker payudara jadikannya penyebab kematian tertinggi. Retrieved from http://lifestyle.okezone.com/read/2016/09/07/481/1483703/banyaknya-pemicu-kankerpayudara-jadikannya-penyebab-kematian-tertinggi-di-indonesia

Kementerian Kesehatan RI. (2015). Data Penyakit Kanker. InfoDATIN pusat data dan informasi kementerian kesehatan RI. Retrieved from http://www.depkes.go.id/resources/download/pusdatin/infodatin/infodatin-kanker.pdf

Manafe, D (2014, Februari 5). Di Indonesia, kasus kanker payudara dan serviks tertinggi. Retrieved from http://www.beritasatu.com/kesehatan/164592-di-indonesia-kasus-kanker-payudara-danserviks-tertinggi.html

Peterson, C. (2006). A primer in positive psychology. Oxford : Oxford University Press.

Primardi, A., Hadjam, M. N. R. (2010). Optimisme, harapan, dukungan sosial, keluarga, dan kualitas hidup orang dengan epilepsi. Jurnal Psikologi, 3(2).

Riady, J. (2013). 60\% Pasien Kanker Payudara di RS Dharmais Datang Pada Stadium Lanjut. Retrieved from http://sp.beritasatu.com/home/60-pasien-kanker-payudara-di-rs-dharmaisdatang-pada-stadium-lanjut/43671

Sari, Q. N. R. (2012). Dukungan sosial pada penderita kanker payudara di masa dewasa tengah.

Suharmilah., Setyaningsih, T. R. B., Wijayana, K. A. (2013). Faktor-faktor yang berhubungan dengan tingkat depresi pada pasien kanker payudara yang sudah mendapatkan terapi di Rumah Sakit Margono Soekarjo Purwokerto. Mandala of Health, 6(1).

Wardiyah, A., Afiyanti, Y., Budiati, T. (2014). Faktor yang mempengaruhi optimisme kesembuhan pada pasien kanker payudara. Jurnal Keperawatan, 5(2).

Winda, A., Sudiantara, Y. (2014). Hardiness pada wanita penderita kanker payudara.

Yayasan Kanker Indonesia Provinsi DKI Jakarta. (2015). Deteksi dini kanker payudara. Flyer. 